\title{
Nitric oxide but not carbon monoxide is continuously released in the human nasal airways
}

\author{
J.O.N. Lundberg*, J. Palm*,\#, K. Alving*
}

\begin{abstract}
Nitric oxide but not carbon monoxide is continuously released in the human nasal airways. J.O.N. Lundberg, J. Palm, K. Alving. C) ERS Journals Ltd 2002.

ABSTRACT: Results from different laboratories indicate that nitric oxide (NO) and carbon monoxide (CO) coexist in the human airways both in health and disease. These gases are present in exhaled human breath and high concentrations of NO as well as $\mathrm{CO}$ have been reported in the nasal airways. In addition, exhaled $\mathrm{CO}$ and NO are increased in patients with airways inflammation. NO and $\mathrm{CO}$ were measured simultaneously in orally exhaled air and in air sampled from the nose in 18 healthy subjects using chemiluminescence (for NO) and infrared (for $\mathrm{CO}$ ) techniques at different fixed flow rates. The acute effects of smoking on airway release of NO and CO were also studied.

Nasal NO was detected in all subjects and the concentrations were highly flowdependent (mean \pm SEM: $236 \pm 23$ and $527 \pm 49$ parts per billion (ppb), at 2 and $0.5 \mathrm{~L} \cdot \mathrm{min}^{-1}$, respectively). In contrast, no evidence of $\mathrm{CO}$ release in the nasal airways regardless of sample flow rate was found. In fact, additional experiments indicated a net absorption of $\mathrm{CO}$ when low levels of this gas were flushed through the nasal cavity. Nasal CO also remained undetectable after smoking. Both NO (22 $\pm 2 \mathrm{ppb})$ and CO $(1.1 \pm 0.1$ parts per million) were consistently found in orally exhaled air. $\mathrm{CO}$, but not NO, levels increased acutely after smoking a cigarette.

The authors conclude that the patterns of nitric oxide and carbon monoxide release in the airways seem to differ profoundly in healthy subjects. Orally exhaled air contains both nitric oxide and carbon dioxide whereas nasal air contains nitric oxide only. Eur Respir J 2002; 19: 100-103.
\end{abstract}

*Dept Physiology and Pharmacology, Karolinska Institute and ${ }^{\#}$ Dept OtoRhino-Laryngology, Huddinge University Hospital, Stockholm, Sweden.

Correspondence: J.O.N. Lundberg, Dept Physiology and Pharmacology, Karolinska Institutet 171 77, Stockholm, Sweden.

Fax: 468332278

E-mail: jon.lundberg@fyfa.ki.se

Keywords: Asthma, breath test, exhaled air, rhinitis, sinuses, sinusitis

Received: November 82001

Accepted after revision: February 13 2002

This study was supported by grants from The Swedish Research Council, The Heart \& Lung Foundation, The Karolinska Institutet and Ruth \& Richard Juhlins Foundation.
Measurements of airway-derived nitric oxide (NO) have received a lot of attention over the past decade [1-3]. Exhaled NO is increased in asthma [2] and suggestions have been made that this noninvasive test can be used to monitor airways inflammation. In healthy subjects NO release in the lower airways is generally low [4]. In contrast, high levels of NO are found in the nasal airways of healthy subjects [4]. Parts of the NO found in nasally derived air is produced in the paranasal sinuses, where a high-rate producing inducible NO synthase is constantly expressed [5].

The finding that $\mathrm{NO}$ is released at different levels in the respiratory system in health and disease has triggered an interest in also measuring other gaseous compounds in exhaled breath. Recently, there have been several reports on increased levels of exhaled carbon monoxide (CO) in patients with airways inflammation [6-17]. In addition, it has also been suggested that $\mathrm{CO}$ is released in the nose and paranasal sinuses of healthy people [18]. Thus, it seems as though $\mathrm{NO}$ and $\mathrm{CO}$ coexist in the airways both in health and disease. Despite the relatively large numbers of studies looking at the airway release of NO or CO there have been few attempts to measure both gases simultaneously in healthy subjects using standardised procedures. The current authors therefore, decided to study the levels of both NO and $\mathrm{CO}$ in healthy subjects at different levels of the respiratory tract.

\section{Materials and methods}

\section{Study subjects}

A total of 18 nonsmoking or occasionally smoking volunteers (aged 24-46 yrs, seven females) participated in the study. All were healthy without any ongoing infection or history of airway disease. In all the subjects $\mathrm{NO}, \mathrm{CO}$ and carbon dioxide $\left(\mathrm{CO}_{2}\right)$ levels were measured in nasal air as well as orally exhaled air. In addition, in seven of the subjects (the occasional smokers, aged 33-37 yrs, one female) airway release of $\mathrm{NO}$ and $\mathrm{CO}$ was also measured 5 min after smoking a cigarette. None had smoked within 2 days prior to the study. The study was approved by the local Ethics Committee, and informed consent was obtained from each volunteer.

\section{Collection of nasal air}

A tightly fitting nasal olive was introduced into one nostril. The olive was connected to a suction pump 
and flow was adjusted to $0.5,1$ or $2 \mathrm{~L} \cdot \mathrm{min}^{-1}$. Aspirated air was led into a nonreactive polyurethane bag $(0.6 \mathrm{~L})$ impermeable to $\mathrm{NO}$ and $\mathrm{CO}$. During sampling the subjects were asked to hold their breath with the mouth closed forcing air to flow from one nostril to the other via the nasopharynx. Sampling was initiated immediately following nasal inspiration to total lung capacity (TLC). To assure zero inlet levels of $\mathrm{CO}$ and $\mathrm{NO}$ a second olive was introduced into the other nostril and further connected to a clean-air reservoir. NO- and $\mathrm{CO}$-free air was generated by feeding medical breathing air (AGA AB, Stockholm, Sweden) through a Purafill drypowder scrubber and an electronic scrubber (Alphagaz air flow, Air Liquide Gas AB, Kista Sweden).

In five of the subjects $\mathrm{CO}$ was also measured in air (1.4 parts per million (ppm) CO) that had passed through the nose from one nostril to the other. The aspirating $\left(0.5 \mathrm{~L} \cdot \mathrm{min}^{-1}\right)$ sampling tube of the $\mathrm{CO}$ analyser (see below) was connected to an olive and introduced into one nostril. A second olive was connected to the bag with CO-containing air and introduced in the other nostril. During sampling the subjects were asked to hold their breath. When measuring nasal $\mathrm{NO}$ and $\mathrm{CO}$ after smoking a cigarette the flow of $2 \mathrm{~L} \cdot \mathrm{min}^{-1}$ was used.

\section{Collection of orally exhaled air}

The subjects inhaled to TLC from a clean-air reservoir and exhaled after a breath-hold of $5 \mathrm{~s}$. The first portion of exhaled air was discarded, whereas the last portion was collected at a flow rate of $40-50 \mathrm{~mL} \cdot \mathrm{s}^{-1}$ in a polyurethane bag for immediate analysis of $\mathrm{NO}, \mathrm{CO}$ and $\mathrm{CO}_{2}$.

\section{Analysis of nitric oxide carbon monoxide and carbon dioxide}

Analysis of the gases in the polyurethane bags was carried out within 1 min of airway sampling starting with $\mathrm{CO}_{2}$ followed by $\mathrm{NO}$ and $\mathrm{CO}$. $\mathrm{CO}_{2}$ was measured with an infrared (IR) technique (Capnomac, Datex, Sweden), as was CO (NDIR analyser, UNOR 610; Maihak AG, Hamburg, Germany) and NO with chemiluminescence (AM 77 Eco Physics, Switzerland). Sample air was dehumidified with Naphion membranes before $\mathrm{NO}$ and $\mathrm{CO}$ analyses. The detection limits for $\mathrm{CO}_{2}, \mathrm{CO}$ and $\mathrm{NO}$ were $0.2 \%, 0.1 \mathrm{ppm}$ and 1 parts per billion (ppb)/ respectively. In all cases the amount of air in the bag was sufficient to give a full recovery of the signal by the three different analysers. The stability of the gases in the polyurethane bags was tested in some cases by measuring $\mathrm{NO}, \mathrm{CO}$ and $\mathrm{CO}_{2}$ once again 3 min later which gave the same result (data not shown). A two-point calibration was performed for all three analysers using medical breathing air (zero point calibration) and synthetic gas mixtures in nitrogen (10 ppm NO, $20 \mathrm{ppm} \mathrm{CO}$ and $5 \% \mathrm{CO}_{2}$, AGA AB, Lidingö, Sweden).

During the experiments ambient levels of NO and $\mathrm{CO}$ never exceeded $10 \mathrm{ppb}$ and $0.1 \mathrm{ppm}$, respectively.

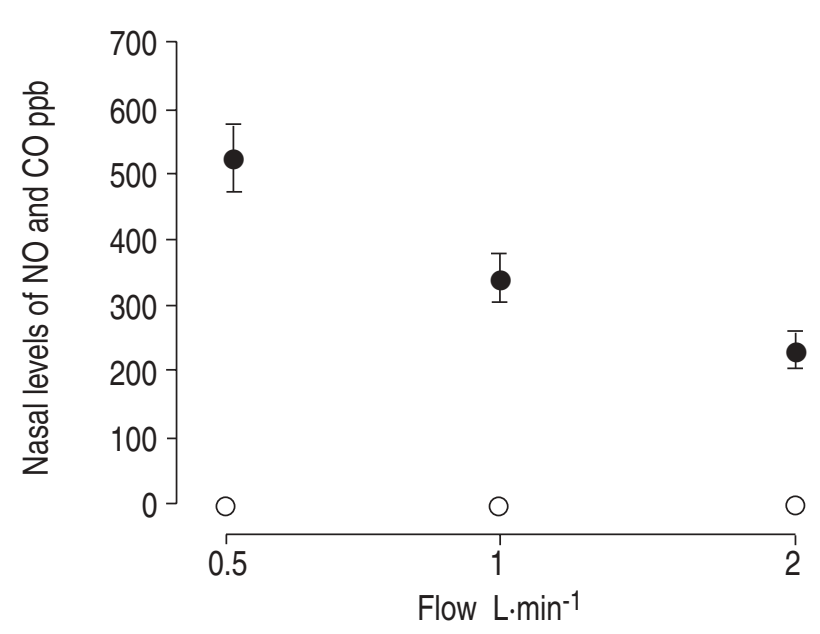

Fig. 1. - Levels (mean \pm SEM) of nitric oxide (NO: O) and carbon monoxide (CO: $\bigcirc$ ) in air flushed through the nose at three different flow rates $(n=18)$. ppb: parts per billion.

\section{Results}

\section{Nasal sampling}

Nasal NO was flow-dependent with the mean \pm SEM being: $236 \pm 23 \mathrm{ppb}$ at $2 \mathrm{~L} \cdot \mathrm{min}^{-1}, 347 \pm 31 \mathrm{ppb}$ at $1 \mathrm{~L} \cdot \mathrm{min}^{-1}$ and $527 \pm 49 \mathrm{ppb}$ at $0.5 \mathrm{~L} \cdot \mathrm{min}^{-1}$. Nasal $\mathrm{CO}$ and $\mathrm{CO}_{2}$ signals were below the detection limit of the analysers in every subject at all flow rates (fig. 1). CO levels also remained undetectable after smoking a cigarette (fig. 2).

When CO (1.4 ppm) was flushed through the nose from one nostril to the other the $\mathrm{CO}$ signal decreased by $0.3-0.8 \mathrm{ppm}$, with a mean of $0.54 \mathrm{ppm}$.

\section{Orally exhaled air}

NO was found at a level of $22 \pm 2 \mathrm{ppb}$ in orally exhaled air. $\mathrm{CO}$ was detected in all subjects with a

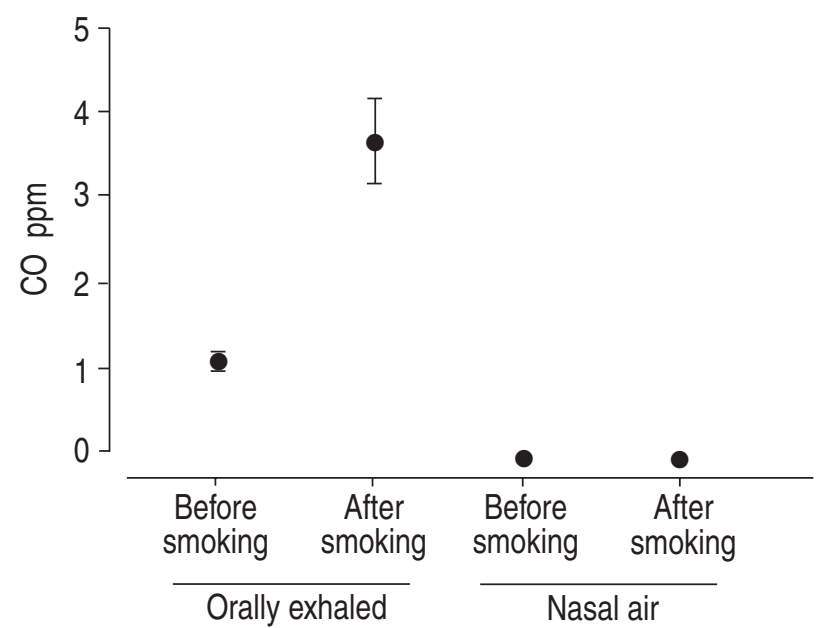

Fig. 2. - The effect of smoking on levels (mean \pm SEM) of carbon monoxide (CO) in orally exhaled air and in air derived from the nasal cavity (nasal air). Measurements $(n=7)$ were made 5 min after smoking one cigarette. ppm: parts per million. 
mean value of $1.1 \pm 0.1 \mathrm{ppm}$ (range $0.3-2.1 \mathrm{ppm}$ ). The $\mathrm{CO}_{2}$ signal was $4.8 \pm 0.1 \%$. Smoking a cigarette caused a three-fold rise in $\mathrm{CO}$ (from $1.2 \pm 0.2$ to $3.7 \pm 0.5 \mathrm{ppm}$ ) whilst NO remained unchanged ( $20 \pm 3$ before smoking versus $21 \pm 2 \mathrm{ppb}$ after smoking).

\section{Discussion}

The authors attempted to study $\mathrm{NO}$ and $\mathrm{CO}$ simultaneously in nasal air as well as in orally exhaled air. This was achieved by collecting the airway samples in bags followed by immediate analyses of both $\mathrm{NO}$ and $\mathrm{CO}$. On-line measurements of the gases would have given more information about the dynamics in a single oral exhalation. However, since the response time of the analysers differed greatly, an exact integration of all three signals would have been difficult to achieve. For nasal measurements a method where air was sampled from the nasal cavity, at a fixed flow rate, and collected in nonreactive gas impermeable bags was used. Analysis of $\mathrm{NO}, \mathrm{CO}$ and $\mathrm{CO}_{2}$ were performed within $1 \mathrm{~min}$ of collecting the air. Since both NO and CO are normal constituents of the environment, caution was taken to secure a zero inflow of these gases during nasal sampling. The absence of $\mathrm{CO}_{2}$ in all nasal samples assured that lower airway gases had not mixed with nasal air during sampling. Conversely, an alveolar origin of exhaled gases was verified by the presence of $\mathrm{CO}_{2}$ during oral exhalation. As predicted [4], NO was low in orally exhaled air and high in nasal air. Moreover, nasal NO was highly flow-dependent with higher levels obtained at a low flow. Exhaled or nasal NO, as measured 5 min after smoking, was not affected by cigarette smoking.

$\mathrm{CO}$ was present in orally exhaled air. The levels of $\mathrm{CO}$ in orally exhaled air exceeded NO by a factor of 30 , and increased as predicted after smoking a cigarette. In contrast, no evidence of $\mathrm{CO}$ release in the nasal airways was found. If $\mathrm{CO}$ was continuously produced, and released in significant amounts in the nasal airways one would expect a flow-dependency in the obtained values as observed for NO. However, the authors were unable to detect any $\mathrm{CO}$ signal in nasal air even at the lowest flow-rates used. The high levels of NO in the very same sample bag confirmed the true nasal origin of this air. Moreover, the absence of $\mathrm{CO}_{2}$ in the nasal samples did exclude the possibility of contamination with lower airway gases.

The IR technique used for $\mathrm{CO}$ measurements is considered very accurate for measuring $\mathrm{CO}$ even in the sub-ppm range. Indeed, the capability of the analyser to detect low levels of $\mathrm{CO}$ in this set-up was verified by the oral measurements, where a clear CO signal was uniformly seen in all subjects $(0.3-$ $2.1 \mathrm{ppm})$. In fact, even a 10 -fold dilution of orally exhaled air $(\mathrm{CO}=2.0 \mathrm{ppm})$ with zero air gave a clear signal of $0.2 \mathrm{ppm}$, which is close to the detection limit of the analyser (data not shown). Obviously, the fact that $\mathrm{CO}$ may be released in the nose at levels lower than this cannot be excluded. ANDERSSON et al. [18] reported nasal and sinus levels of $\mathrm{CO}>1 \mathrm{ppm}$, which is in sharp contradiction to the present findings. The reason for the discrepancy between the two studies can only be speculated upon. Nevertheless, there are some methodological differences between the two studies. In the study by ANDERSSON et al. [18] ambient $\mathrm{CO}$ levels were much higher $(0.75 \mathrm{ppm})$ and these were subtracted from the obtained values. The present study used CO-free air, which was introduced in the contralateral nostril during sampling. Moreover, ambient $\mathrm{CO}$ levels were very low throughout the experimental period. It could be speculated that in areas of high ambient $\mathrm{CO}$ levels, this gas is absorbed into the blood or mucus and slowly released in the nose during a long period of time after exposure. This has been well characterised for orally exhaled $\mathrm{CO}$ where the levels are increased a long period of time after smoking a CO-containing cigarette, and this is due to the rather slow uncoupling of $\mathrm{CO}$ from haemoglobin. However, in this study no increase in nasal $\mathrm{CO}$ after smoking was found, indicating that any passage of $\mathrm{CO}$ from the blood to the nasal cavity is low. ANDERSSON et al. [18] sampled nasal air during tidal breathing through the mouth as one part of the study. This approach would increase the risk for contamination with lower airway $\mathrm{CO}$ to nasal air. However, this still does not explain the high $\mathrm{CO}$ signal found in nasal air in two subjects breathing through a tracheostoma thereby excluding contamination from the lower airways.

When flushing the nasal cavity with $\mathrm{CO}$-containing synthetic air (1.4 ppm CO) it was observed that CO levels dropped by $0.3-0.8 \mathrm{ppm}$ during passage from one nostril to the other. This indicated a net absorption of $\mathrm{CO}$ by the nasal mucosa. Thus, rather than being continuously released in the nose from cellular sources it seems as if this gas, in part, is taken up by the mucosa. An alternative explanation is that the $\mathrm{CO}$ signal is quenched by some factor in the nose, e.g. water vapour. However, this is less likely since mixing of synthetic $\mathrm{CO}$ at a known concentration with either nasally derived air or synthetic dry air gave the same $\mathrm{CO}$ signal (unpublished observation). Furthermore, according to the manufacturer the maximum quenching by water vapour or $\mathrm{CO}_{2}$ is $<2 \%$.

As mentioned above nasal $\mathrm{NO}$ is strongly flowdependent and earlier studies have shown that this is also true for orally exhaled NO [3, 19]. The flowdependency of both NO and CO in orally exhaled air was studied recently by ZETTERQuist et al. [20]. It was shown that orally exhaled $\mathrm{CO}$ is not flow-dependent, whereas NO is. This strongly indicates that NO originates predominantly in the airways whereas $\mathrm{CO}$ is of alveolar origin.

To conclude, the airway release of nitric oxide and carbon monoxide seem to differ profoundly with regards to the amount and location in healthy subjects. Nasal air contains high levels of nitric oxide but no carbon monoxide, whereas air from the lower airways and lungs contains both nitric oxide and carbon monoxide.

\section{References}

1. Gustafsson LE, Leone AM, Persson MG, Wiklund NP, Moncada S. Endogenous nitric oxide is present in 
the exhaled air of rabbits, guinea pigs and humans. Biochem Biophys Res Commun 1991; 181: 852-857.

2. Alving K, Weitzberg E, Lundberg JM. Increased amounts of nitric oxide in exhaled air of asthmatics. Eur Respir J 1993; 6: 1368-1370.

3. Lundberg JON, Weitzberg E, Lundberg JM, Alving K. Nitric oxide in exhaled air. Eur Respir J 1996; 9: 2671-2680.

4. Lundberg JON, Weitzberg E, Nordvall SL, Kuylenstierna R, Lundberg JM, Alving K. Primarily nasal origin of exhaled nitric oxide and absence in Kartagener's syndrome. Eur Respir J 1994; 7: 1501-1504.

5. Lundberg JON, Farkas-Szallasi T, Weitzberg E, et al. High nitric oxide production in human paranasal sinuses. Nature Med 1995; 1: 370-373.

6. Paredi P, Leckie MJ, Horvath I, Allegra L, Kharitonov SA, Barnes PJ. Changes in exhaled carbon monoxide and nitric oxide levels following allergen challenge in patients with asthma. Eur Respir $J$ 1999; 13: 48-52.

7. Paredi P, Kharitonov SA, Leak D, et al. Exhaled ethane is elevated in cystic fibrosis and correlates with carbon monoxide levels and airway obstruction. Am J Respir Crit Care Med 2000; 161: 1247-1251.

8. Antuni JD, Kharitonov SA, Hughes D, Hodson ME, Barnes PJ. Increase in exhaled carbon monoxide during exacerbations of cystic fibrosis. Thorax 2000; 55: $138-142$.

9. Scharte $\mathbf{M}$, Bone $\mathrm{HG}$, Van Aken H, Meyer J. Increased carbon monoxide in exhaled air of critically ill patients. Biochem Biophys Res Commun 2000; 267: 423-426.

10. Uasuf CG, Jatakanon A, James A, Kharitonov SA, Wilson NM, Barnes PJ. Exhaled carbon monoxide in childhood asthma. J Pediatr 1999; 135: 569-574.

11. Monma M, Yamaya M, Sekizawa K, et al. Increased carbon monoxide in exhaled air of patients with seasonal allergic rhinitis. Clin Exp Allergy 1999; 29: $1537-1541$.
12. Paredi P, Shah PL, Montuschi P, et al. Increased carbon monoxide in exhaled air of patients with cystic fibrosis. Thorax 1999; 54: 917-920.

13. Yamara M, Sekizawa K, Ishizuka S, Monma M, Sasaki H. Exhaled carbon monoxide levels during treatment of acute asthma. Eur Respir J 1999; 13: 757-760.

14. Horvath I, Loukides S, Wodehouse T, Kharitonov SA, Cole PJ, Barnes PJ. Increased levels of exhaled carbon monoxide in bronchiectasis: a new marker of oxidative stress. Thorax 1998; 53: $867-870$.

15. Horvath I, Donnelly LE, Kiss A, Paredi P, Kharitonov SA, Barnes PJ. Raised levels of exhaled carbon monoxide are associated with an increased expression of heme oxygenase-1 in airway macrophages in asthma: a new marker of oxidative stress. Thorax 1998; 53: 668-672.

16. Yamaya M, Sekizawa K, Ishizuka S, Monma M, Mizuta K, Sasaki H. Increased carbon monoxide in exhaled air of subjects with upper respiratory tract infections. Am J Respir Crit Care Med 1998; 158: 311-314.

17. Zayasu K, Sekizawa K, Okinaga S, Yamaya M, Ohrui $\mathrm{T}$, Sasaki H. Increased carbon monoxide in exhaled air of asthmatic patients. Am J Respir Crit Care Med 1997; 156: 1140-1143.

18. Andersson JA, Uddman R, Cardell LO. Carbon monoxide is endogenously produced in the human nose and paranasal sinuses. J Allergy Clin Immunol 2000; 105: 269-273.

19. Silkoff P, McClean P, Slutsky A, et al. Marked flowdependence of exhaled nitric oxide using a new technique to exclude nasal nitric oxide. Am J Respir Crit Care Med 1997; 155: 260-267.

20. Zetterquist W, Marteus H, Johannesson M, et al. Exhaled carbon monoxide is not elevated in patients with asthma or cystic fibrosis. Eur Respir J 2002; 20: 92-99. 